\title{
La comunicación en el marco de la Responsabilidad Social Bases para una definición de Comunicación Responsable
} Communication in the context of Social Responsibility Basis for a Definition of Responsible Communication

Susana de Andrés del Campo Universidad de Valladolid delcampo@hmca.uva.es

Rodrigo González Martín Universidad de Valladolid rogonmar@hmca.uva.es 


\section{Clasificación JEL: \\ M14, M3}

Palabras clave:

Comunicación

responsable,

responsabilidad

social empresarial,

libro blanco,

libro verde.
El propósito de este texto es ofrecer una aproximación general a la idea de comunicación responsable, sobre la indagación conceptual de las relaciones de significado entre responsabilidad y comunicación. A partir de un análisis de las referencias incluidas en dos de los documentos marco para la promoción de la RSE, como son el Libro Verde y el Libro Blanco, se extraen y analizan las dos principales condiciones de la comunicación responsable: transparencia y diálogo. Sobre ambos pilares conceptuales el artículo inicia una construcción teórica para la definición de comunicación responsable y plantea, a partir de dicha reflexión, diversas reorientaciones que dicha definición implicaría en la utilización de las herramientas de la comunicación de las organizaciones.

Desde un enfoque categorial se pretende ofrecer una reflexión que clarifique y ahonde en la Comunicación Responsable como eje crucial de los compromisos y valores asumidos por la entidad o corporación en su relación compleja con los sujetos que interactúen en la actividad y gestión que desarrolle. Se aportan las bases conceptuales primarias para hablar con el mayor rigor posible de la Comunicación Responsable más allá de modas del mercado, de urgencias de las crisis o de imperativos condicionados por los diferentes modelos utilizados. El artículo termina proponiendo una definición teórica y maximalista de comunicación responsable y desglosando los aspectos que dicha definición implicaría.
JEL Classification:

M14, M3

Key words:

Responsible communication, corporate social responsibility, white paper, green paper.
The purpose of this work is to provide a general approach to the idea of responsible communication, a conceptual investigation of the relationship between the meanings of responsibility and communication. Starting from an analysis of the references included in the Green Paper and the White Paper, two framework documents for the promotion of CSR, we extract and analyse the two main conditions for Responsible Communication: transparency and dialogue. Based on these conceptual pillars, the article develops a theoretical construct for the definition of Responsible Communication and, from this reflection, raises several reorientations that this definition implies for the use of communication tools within organisations.

Based on a categorical approach, the aim is to offer a reflection which clarifies and looks deeper into Responsible Communication as a crucial axis of the commitments and values assumed by businesses and corporations in their complex relationship with those subjects with whom they interact in the development and management of their activity. We provide the primary conceptual basis to discuss Responsible Communication with the utmost rigor, beyond market trends, crises or other imperatives conditioned by the different models employed. The article concludes by proposing a theoretical and maximalist definition of Responsible Communication and breaking down the aspects that this definition would imply. 


\section{Introducción ${ }^{1}$}

La responsabilidad social está reorientando las prácticas de las organizaciones e instalándose en su discurso. Son muchas las iniciativas internacionales que promueven su transversalidad. Pero su planteamiento se realiza principalmente desde la práctica, se ilustra con ejemplos y se plantea desde acciones específicas. Desde los grandes textos de referencia tanto nacionales como internacionales, a la enorme casuística acumulada en todo tipo de foros y debates, se ha potenciado el enfoque práctico, incluso accionista, de la Responsabilidad Social, considerando que se trata de elaborar programas de actividades de todo tipo vinculadas a los objetivos estratégicos a corto o medio plazo de la corporación y su ámbito de actuación.

El propio Libro Blanco de la Comisión del Ministerio de Trabajo y Asuntos Sociales (2006:13), contextualiza así la actual comprensión de la responsabilidad social:

“... suele tener un marcado carácter $<<$ activo $>$, práctico, vinculado más a la conjugación del verbo $<<$ hacer $>$ que no a una presentación teórica o de grandes principios"

Pero incluso en una deriva practicista, la reflexión teórico-conceptual es sumamente necesaria para evitar ambigüedades. Al debatir sobre la RSE se debiera tratar de consensuar no sólo las

1 Este artículo resume el estudio conceptual sobre la comunicación responsable realizado dentro del marco del proyecto de investigación "Innovación en la imagen y comunicación de la discapacidad intelectual. Proyecto de acciones integradas sobre creatividad responsable y análisis de su eficacia en el cambio de conocimiento y actitudes hacia las personas con discapacidad intelectual". Código Ref. VA002B10-1. Proyecto elaborado en colaboración y con el apoyo de FEAPS Castilla y León. Federación de entidades, asociaciones y fundaciones de personas con discapacidad intelectual y sus familias, de Castilla y León. acciones, sino los fines, y las ideas que subyacen a los términos o conceptos utilizados.

Lo mismo ocurre con la comunicación en el marco de la responsabilidad social, ámbito de discusión que ya propicia literatura y foros, en los que se suelen condensar ejemplos de buenas prácticas, casos y testimonios, también análisis estructurales y funcionales. Pero el debate teórico de la comunicación responsable apenas es abordado, y la literatura científica sobre la responsabilidad social no cuenta con muchos trabajos elaborados desde las áreas de la comunicación.

Este artículo pretende iniciar una discusión conceptual sobre la idea de comunicación responsable, a partir de la atención a los términos principales de su marco de consenso (extraída a partir de documentos oficiales) y avanzar hacia una definición teórica (como concepto proyectivo de máximos).

Este texto se sitúa fácilmente en las Recomendaciones 39 y 52 del citado Libro Blanco (2006), en las que se propone fomentar la investigación de la RSE en universidades y Escuelas de Negocios.

\section{Planteamiento del estudio}

El propósito de este texto es ofrecer una aproximación genérica al concepto de comunicación responsable en el entorno de la Responsabilidad Social, desde cualquier adjetivación que le demos, sea Empresarial, Corporativa, Institucional, Universitaria, sobre la hipótesis de que la Comunicación Responsable no es un conjunto de mediosy prácticas (elaborar soportes de información, reportes e informes, cuestaciones de opinión, mesas de diálogo, etc. ) sino que depende de los fines sociales que se asuman y cómo estos orienten su planificación, creación de mensajes y desarrollo mediático. 
De las numerosas iniciativas que constituyen el marco nacional e internacional desde el que se promueve la responsabilidad social empresarial (normas, tratados, directrices, acuerdos e instrumentos), analizamos en este artículo dos de los documentos que están jugando un importante papel en la consolidación y consenso del concepto de responsabilidad social: el Libro Verde (2001) de la Comisión de las Comunidades Europeas para propiciar un marco europeo para la Responsabilidad Social de las Empresas y el Libro Blanco (2006) aprobado por la Comisión de Trabajo y Asuntos Sociales sobre el informe de la Subcomisión para potenciar y promover la responsabilidad social de las empresas. El análisis identifica y extrae las referencias a la comunicación en dichos libros marco, e indaga en la visión del papel de la comunicación dentro de la política de promoción de la RSE, así como anticipar nuevos perfiles profesionales y competencias en Comunicación Responsable ${ }^{2}$

\section{Aproximación a las relaciones conceptuales entre comunicación y responsabilidad}

Responsabilidad, etimológicamente viene del latín respondere: responder. Desde el origen del término mismo, es fácil de comprobar la relación intrínseca que el concepto de responsabilidad, tiene con los de comunicación y diálogo. A su vez, la idea original de responder, vemos que partía de la importancia de la medida, del peso (pondus), en una interacción, más que de los medios utilizados o de la obligación de la respuesta. Conviene incidir en el sentido original de respuesta medida, equilibrada, ajustada, para desvelar el

2 Una reflexión sobre la integración de estos perfiles en los currícula universitarios del marco EEES puede encontrarse en Andrés, S. de y González, R. (2010, 66-81). sentido esencial de comunicación responsable. La responsabilidad, como respuesta, correspondencia, réplica, equiparación, equilibrio o armonía, surge en un contexto etológico (respuesta de un animal a otro), verbal (respuesta a la llamada), artístico incluso (respuesta recitativa en una salmodia), o lógico y cognitivo (satisfacción a un argumento o duda), para con posterioridad pasar a adquirir otros significados morales (asumir las consecuencias de una acción libre) o jurídicos (obligación de reparar o satisfacer una deuda o compromiso).

Dentro de este amplio campo semántico, El Diccionario de la RAE (edición $22^{\circ}$ ) define el adjetivo responsable en su segunda acepción como:

Dicho de una persona: Que pone cuidado y atención en lo que hace o dice.

Esta acepción desvela las claves de la responsabilidad desde el cuidado en el hacer y el decir. El sentido de responsabilidad queda aquí muy cerca de la vieja máxima "hacerlo bien y hacerlo saber", tomada como definición propositiva de las mejores intenciones de las relaciones públicas. Responsable es responder, pero sobre todo importa cómo se responda, el cuidado de esa respuesta.

Muchas de las más recientes definiciones de responsabilidad social incluyen el diálogo en su definiens. Una definición consensuada y plural a tomar como referencia puede ser la emitida por el Foro de Expertos en Responsabilidad Social de las Empresas, constituido el 17 de marzo de 2005 por iniciativa del Ministerio de Trabajo y Asuntos Sociales (Ferreiro, 2008:5), que definía así Responsabilidad Social Empresarial:

La responsabilidad social de la empresa es, además del cumplimiento estricto de las obligaciones legales vigentes, la integración voluntaria por parte de la empresa, en su gobierno y gestión, en su 
estrategia, políticas y procedimientos, de las preocupaciones sociales, laborales, medio ambientales y de respeto a los derechos humanos que surgen de la relación y el diálogo transparentes con sus grupos de interés, responsabilizándose así de las consecuencias y de los impactos que derivan de sus acciones.

Desde esta definición se entiende que la responsabilidad social de las empresas emana del diálogo, de la comunicación con sus públicos. Puede deducirse que la comunicación, transparente y evaluada, sería la base de posibilidad para la responsabilidad social de las empresas.

Partimos pues de la interrelación existente entre los conceptos de responsabilidad y diálogo, deduciendo que un concepto nos lleva al otro. Cabe pues analizar, de manera más pormenorizada, cuáles son las concreciones de estas referencias a la comunicación dentro del marco emergente e ineludible de la Responsabilidad Social (empresarial o corporativa).

\section{Referencias a la comunicación en los documentos marco para la promoción de la responsabilidad social empresarial}

Del concepto a la pragmática, es significativa la afirmación del presidente de Dircom, Asociación de Directivos de Comunicación de España, José Manuel Velasco: "Una comunicación responsable es sinónimo de gestión responsable” ( 2009:12).

Siendo tan importante el papel de la comunicación en el nuevo marco de la responsabilidad social empresarial, es importante indagar, de manera pormenorizada, en su alusión en los documentos marco que ocupan un lugar preferente en la promoción europea de la RSE. Se ha escogido uno de esos documentos de consenso internacional: El Libro Verde ${ }^{3}$ europeo de la Responsabilidad Social Empresarial, y otro de consenso nacional, el Libro Blanco4.

A continuación se expone la forma en la que estos documentos hacen alusión a la comunicación en relación a la RSE $\mathrm{R}^{5}$. En la siguiente tabla se muestran los conceptos más referenciados en relación con la comunicación en uno y otro documento. Los tres conceptos más veces indexados en la contabilización del análisis de ambos textos son Información/es, Transparencia y Diálogo:

Tabla 1 · Contabilización terminológica. Elaboración propia

\begin{tabular}{|l|r|r|}
\hline Palabra & \multicolumn{1}{|l|}{$\begin{array}{l}\text { Libro } \\
\text { verde }\end{array}$} & $\begin{array}{l}\text { Libro } \\
\text { blanco }\end{array}$ \\
\hline Información/es & 30 & 131 \\
\hline Transparencia & 11 & 97 \\
\hline Diálogo & 14 & 52 \\
\hline Informes & 30 & 29 \\
\hline Relaciones con & 15 & 18 \\
\hline Medios de comunicación & 0 & 31 \\
\hline Publicidad & 0 & 11 \\
\hline
\end{tabular}

3 Libro Verde: Fomentar un marco europeo para la responsabilidad social de las empresas Comisión de las Comunidades Europeas. Bruselas, 18.07.2001. Disponible en http://www.jussemper.org/Inicio/ Recursos/Actividad\%20Corporativa/Resources/Libro\%20verde.pdf

http://www.jussemper.org/Inicio/Recursos/Actividad\%20Corporativa/Resources/Libro\%20verde.pdf

4 Informe de la Subcomisión Parlamentaria sobre Responsabilidad Social presentado el 13 de diciembre de 2006, también denominado Libro Blanco de la RSE en España. Boletín Oficial de las Cortes Generales, VIII Legislatura, Serie D: General. 4 de agosto de 2006. № 424C.

5 Conviene recordar que los Libros Blancos son documentos que contienen propuestas de acción comunitaria en un ámbito específico. A veces son la continuación de un Libro Verde publicado con el fin de iniciar un proceso de consulta en el ámbito europeo. Mientras que los Libros Verdes exponen un abanico de ideas con fines de debate público, los Libros Blancos contienen un conjunto oficial de propuestas en ámbitos políticos específicos y constituyen la guía para llevarlas a cabo. 


\begin{tabular}{|l|c|c|}
\hline Publicaciones & 0 & 3 \\
\hline Relaciones públicas & 1 & 2 \\
\hline Identidad corporativa & 0 & 1 \\
\hline
\end{tabular}

En el análisis, encontramos que el marco conceptual para la definición de comunicación responsable estaría compuesto por los conceptos de diálogo, transparencia, información, cohesión social y relación con los públicos, ideas desde las que se incide en la importancia de la comunicación como vía para fomentar la RSE. Indagar en la referencia y conceptualización de estos términos base puede dar apoyatura al objetivo teórico de definir comunicación responsable.

\section{Diálogo y relación con los públicos}

El Libro Blanco (2006:16) incluye, entre sus definiciones de consenso, la siguiente afirmación sobre la RSE:

La construcción de la RSE se produce en el seno de una red de relaciones y marcos de diálogo con los demás actores sociales.

El diálogo es, a partir de proposiciones como ésta, un eje sobre el que vehicular la responsabilidad social empresarial, y en realidad todo ejercicio de responsabilidad social (en instituciones, tercer sector, organizaciones, también familiar, personal...); es incluso el proceso seguido para la elaboración de los documentos marco. En el capítulo I del Libro Blanco, que ocupa aproximadamente el 10\% de su extensión, se analiza cómo se ha trabajado el diálogo social con los grupos de interés que se han consultado y quiénes forman estos grupos de interés.

Diálogo no es, frente a monólogo, comunicación entre dos, ya que dos en griego sería dúo, no dia (José Luís Ramírez; 2003:3). El prefijo día significa a través de, y siguiendo a Ramírez, "habla del medio, no de los interlocutores ni menos aún de su número". Cabe elevar la nueva adjetivación de comunicación dialógica, en el sentido de una comunicación mediadora, constructora de consensos en la sociedad. Pero esta vez, no se trata de buscar etiquetas ni de actualizar el término de comunicación; no cabe esperar un mero adjetivo, sino un nuevo proyecto o ideal de comunicación, o más bien, reivindicar para la comunicación aquello que debió constituir su esencia: el sentido de mediación para la comunidad. Más aún, la lógica de la mediación constructora de valores consensuados. Nos sorprende el significado y validez actual si seguimos el sentido primero del "logos" de Aristóteles (edición 1988:51):

... el lógos sirve para manifestar lo que es conveniente y lo que es perjudicial, así como lo justo y lo injusto. Pues esto es lo que caracteriza al ser humano, distinguiéndole de los demás animales: el hecho de poseer en exclusiva el sentido del bien y del mal, de la justicia y de la injusticia, y de los demás valores. Y la participación en común de estas cosas es constitutiva de la familia y de la comunidad.

En el con quién dialogar se situaría uno de los matices importantes de la comunicación responsable. La responsabilidad social surge y se construye por el diálogo de la comunidad, en la comunidad dialogante. Comunidad, de hecho, es una idea intrínseca al significado de comunicación. Pero la comprensión del complejo significado de comunidad queda restringido, en las referencias de la RSE, a las relaciones con los interlocutores. El Libro Verde de la RSE dedica un apartado a la definición de la RSE, integrando definiciones 
que marcan el énfasis en la relación con los interlocutores, en los puntos 20 y 21 :

20. La mayoría de las definiciones de la responsabilidad social de las empresas entienden este concepto como la integración voluntaria, por parte de las empresas, de las preocupaciones sociales y medioambientales en sus operaciones comerciales y sus relaciones con sus interlocutores.

21. Ser socialmente responsable no significa solamente cumplir plenamente las obligaciones jurídicas, sino también ir más allá de su cumplimiento invirtiendo «más» en el capital humano, el entorno y las relaciones con los interlocutores.

Evidentemente, el concepto de relación es amplio y puede referirse a contratos, convenios, adquisiciones, etc. pero es un aspecto que conecta directamente a la disciplina de las relaciones públicas, marco de acciones que ahora puede verse impulsado desde los parámetros de la responsabilidad social. En este sentido, supone un especial reto originar planificaciones y estrategias de relaciones públicas a nivel internacional y global, sobre todo para empresas implicadas internacionalmente por su red, clientes, consumidores o proveedores. Es de destacar un nuevo concepto emergente que recoge el glosario del Libro Verde: el de ciudadanía corporativa, definido como la gestión de todas las relaciones entre una empresa y sus comunidades de acogida a nivel local, nacional y mundial (op.cit.:).

Las definiciones de responsabilidad social se han relacionado estrechamente con las teorías del management y vemos por ello que la pragmática del diálogo con la comunidad es entendida desde la propuesta de las relaciones con los interlocutores, pero especialmente con los llamados stakeholders (Libro blanco, 2006:16). Según Elsa González (2001:194):
La elección del término stakeholder tiene que ver con la relación fónica y semántica que poseen las dos palabras stakeholder, literalmente "depositario de una apuesta", y Stockholder, que significa accionista. Con esta relación fónica se pretende evocar que en la empresa existen múltiples "depositarios", múltiples grupos relacionados con la empresa y ante los cuales la empresa tiene una responsabilidad.

El concepto de Stakeholder suele ser entendido desde la perspectiva de la empresa e incluso desde la responsabilidad de la empresa. Pero entendiendo el diálogo con la comunidad desde las disciplinas de la comunicación cabe retomar el papel que han de jugar las relaciones públicas en la canalización de estos diálogos. De hecho, es el concepto de público como condición para completar un escenario, el público como proscenio, el que nos llevaría a una propuesta de públicos responsables en relación con empresas y organizaciones, sus funciones y fines, no sólo desde la perspectiva de las empresas sino desde sus propias y plurales perspectivas, influyentes y constructoras de la identidad comprometida de las organizaciones.

La comunicación empresarial con los públicos necesita más que nunca de las relaciones públicas, entendidas desde la ética profesional, en los marcos legales y navegando hacia el matiz de relaciones con públicos corresponsables.

\section{Transparencia e información}

En palabras del director general de la RSE del Ministerio de Trabajo e Inmigración (en Dircom, 2009:10) la crisis económica ha puesto en evidencia que la falta de transparencia ha sido un defecto importante que no debe volver a repetirse. La transparencia se ha convertido en una de las principales señales de responsabilidad social y 
su materialización mediante acciones de comunicación se expresa de forma explícita.

En el resumen del Libro Verde, el punto siete concluye expresando que el objetivo del mismo es iniciar un debate para fomentar la RSE y en particular, entre otros aspectos, para aumentar la transparencia:

7. El presente Libro Verde tiene por objeto iniciar un amplio debate sobre cómo podría fomentar la Unión Europea la responsabilidad social de las empresas a nivel europeo e internacional, en particular sobre cómo aprovechar al máximo las experiencias existentes, fomentar el desarrollo de prácticas innovadoras, aumentar la transparencia e incrementar la fiabilidad de la evaluación y la validación. (...)

A su vez, el punto 10 de la introducción a este libro, sobre los factores que impulsan el avance de la RSE cita concretamente:

La transparencia de las actividades empresariales propiciada por los medios de comunicación y las modernas tecnologías de la información y comunicación.

Pero transparencia es uno de esos conceptos manidos que está recibiendo un sobreabuso, especialmente en el lenguaje político. De hecho, su uso reiterado y sin concreción despierta sospechas de un ejercicio que precisamente puede adolecer de lo que presume. De hecho, en el ámbito de los textos y pactos sobre responsabilidad social, se observa que se ha generado una cierta antinomia entre transparencia y corrupción. Prueba de ello puede ser la conocida organización global Transparency International cuya misión es luchar contra el impacto de la corrupción en la sociedad.

La idea de transparencia no aparece concretada en documentos como el Libro Verde. Pero en estos textos suelen proponerse acciones informativas y de comunicación concretas como la elaboración de publicaciones. Una de las iniciativas que pueden señalar este requerimiento son las Líneas directrices de la OCDE para Empresas Multinacionales. Estas directrices pretenden promover un comportamiento responsable de las empresas multinacionales que voluntariamente se suscriban a este documento. Uno de los diez capítulos en los que se recogen estas directrices es precisamente el de Publicación de Informaciones. A partir de recomendaciones como ésta encontramos el importante papel de emergentes soportes de comunicación empresarial, como son los informes o memorias de RSE. Es evidente que la gestión y elaboración de estos informes es, cada vez más, una de las principales competencias de los Directores de comunicación. Esta política de comunicación responsable respondería al criterio de rendición de cuentas, y conecta con una idea de comunicación basada en la información de hechos o prácticas. Este aspecto es señalado por el libro verde en un punto de casuística sobre la tutoría como acción de responsabilidad social, asistiendo a pequeñas empresas en tareas informativas y divulgativas:

49. Algunas empresas de gran tamaño demuestran su responsabilidad social fomentando el espíritu de empresa en su región de ubicación. Cabe citar, a título de ejemplo, los sistemas de tutoría ofrecidos por las grandes empresas a las empresas de nueva creación y las PYME locales, o la asistencia proporcionada a pequeñas empresas sobre la redacción de informes sociales o la divulgación de sus actividades en el ámbito de la responsabilidad social.

72. Además, es necesario facilitar a las empresas, sobre todo a las PYME, orientación e instrumentos que les permitan informar de manera eficaz 
sobre sus políticas, procedimientos y resultados en el campo de la responsabilidad social. Las grandes empresas pioneras en la materia pueden ayudar en este ámbito a las PYME compartiendo su experiencia y sus conocimientos técnicos.

Siendo la elaboración de informes y memorias (anuales, sectoriales, económicas) una función clásica del departamento de comunicación de la empresa, es de destacar la desconfianza que parece generar el ámbito de las relaciones públicas empresariales, cuando son citadas, de forma específica y negativa, en el Libro Verde:

73. La comprobación por terceros independientes de la información publicada en los informes de responsabilidad social es también necesaria para no dar la impresión de que los informes son meros ejercicios de relaciones públicas sin contenido real. De hecho, ya empieza a haber empresas que ofrecen dichos servicios, que deberían presentarse con arreglo a normas acordadas. La participación de distintos interlocutores, incluidos sindicatos y ONG, podría aumentar la calidad de dicha verificación.

Parece, según se deduce de este punto, que la forma de conseguir que una práctica habitual de las relaciones públicas empresariales como es la elaboración de documentos informativos, sólo podría garantizar sus parámetros de responsabilidad social mediante la auditoría externa. En las recomendaciones del Libro Blanco se penalizan las memorias de sostenibilidad engañosas o falsas, como límite de transparencia para evitar dobles lenguajes en la comunicación externa.

La complejidad, supervisión, crítica y grado de exigencia que caracteriza ya a los informes de responsabilidad social ha hecho surgir iniciativas como Global Reporting Initiative ${ }^{6}$, organización que ofrece pautas y herramientas para la mejor elaboración de informes sociales. A partir del propio Libro Verde se advierte también el nacimiento de un nuevo nicho de especialización en comunicación responsable: las empresas o asesorías especializadas en la realización de informes de RSE.

Además de la referencia a la actividad informativa mediante informes, el Libro Verde dedica un capítulo específico a las etiquetas sociales y ecológicas, otro de los aspectos relacionados con funciones directamente de comunicación. El etiquetado responde históricamente a algunas de las más viejas funciones publicitarias (identificación, diferenciación, garantía). En este apartado el libro se refiere a marcas autodeclaradas, etiquetas sociales y ecológicas de origen no normativo, y lo hace insertando cierto tono preventivo por la dispersión de criterios para otorgarlas ${ }^{7}$, llegando a admitir la escasa credibilidad de las mismas. Se vuelve a señalar que esta práctica comunicativa adolece de falta de transparencia y de verificación independiente. No obstante, se señala el interés por las mismas en nichos crecientes de mercado y de alto poder adquisitivo, pero señala que su eficacia debe mejorarse. He aquí otro de los ámbitos de competencia directa y creciente del director de comunicación responsable.

Pero promover la transparencia parece que lo que ha provocado es cierto accionismo informativo. Hoy podemos constatar fácilmente la avalancha de información sobre RSE. Pero es evidente que generar un exceso de información por

6 http://www.globalreporting.org/ReportingFramework/ G31Guidelines/

7 La organización de referencia en la coordinación de los criterios de etiquetado social o social labelling es Fairtrade Labelling Organizations Internacional: http://www.fairtrade.net/ 
parte de los departamentos de comunicación, aunque sea de calidad y auditada, y provocar su reverberación en los medios, no es sinónimo de transparencia. La comunicación mediática se transforma en un espacio líquido donde dar mera presencia y justificación a las prácticas de RSE.

El concepto de transparencia alude a la idea de apariencia, etimológicamente viene de dos raíces latinas: trans - a través de-y parens, —que aparece-. Su aplicación en el mundo empresarial no conectaría tanto con la emisión de informaciones, como con la idea neurálgica de imagen empresarial o corporativa. Su desarrollo en prácticas comunicativas desde un marco de responsabilidad es evidente que va más allá de la publicación de informes y memorias. No obstante, el concepto de imagen empresarial aparece sólo en un momento del Libro Verde (punto 24) y como ámbito de afectación pasiva, más que como uno de los compromisos activos de la responsabilidad social:

(...) la crítica de las prácticas comerciales desarrolladas por una empresa puede influir a veces negativamente en la opinión que se tiene de ella. Esto puede afectar a los activos fundamentales de la empresa, tales como sus marcas o imagen.

Diálogos, informaciones y relaciones con los públicos son viejas funciones de la comunicación de corporaciones y empresas que inician reorientaciones desde el marco de la responsabilidad social. Pero es quizá el término de identidad -corporativa, empresarial_ - el que mejor sintetiza la construcción de una comunicación participada con los públicos, construida sobre unos valores y capaz de orientar el contexto empresarial y corporativo hacia fines y comprensiones sociales de su misión.

\section{De la comunicación social a la comunicación socialmente responsable}

Dada la importancia de la comunicación en la RSE, conviene asentar los elementos esenciales que contendría el concepto de comunicación responsable, sobre una visión evolutiva del concepto de comunicación empresarial.

En el estudio de las organizaciones, tema fundamental a lo largo de todo el sigo XX, la comunicación ha ido alcanzando un papel relevante tanto en el entorno público como privado. Se suelen resumir en tres grandes escuelas la evolución de las organizaciones (Lucas Marín, A. 1997: 34 ss) que enmarcan el cambiante papel de la comunicación:

La Escuela clásica, llamada la corriente racionalista representada por autores como FW. Taylor, H. Fayol y completada con los trabajos sobre al burocracia de M. Weber, en la que la organización debe funcionar como una máquina con órdenes y tareas precisas. En estos planteamientos la comunicación es entendida como una herramienta que ayuda a definir y a planificar las tareas para se realicen de modo eficaz. En estas teorías raramente se contempla la participación de los sujetos de la organización, tengan el rango que tengan, mediante procesos de comunicativos y menos los ciudadanos ajenos a la misma organización (Carcelén García S., Ruíz San-Román, J. A. y Villagra García, N. 2002:111 ss.)

En los años 30 del siglo pasado surge la llamada Escuela de la Relaciones Humanas, con autores de referencia como E. Mayo, C.I. Barnard, F.J. Roethlirberger y W.J. Dickson, en la que la comunicación empieza a ser tenida en cuenta para alcanzar una mayor satisfacción de las personas que intervienen en la organización y todo con una finalidad manifiesta, la de lograr una mayor 
productividad. La comunicación se ve desde la óptica de una mayor colaboración de los sujetos implicados en el proceso productivo, incentivando una mayor participación, incluso una relativa interacción en la mejora de los procesos y en la resolución de los posibles problemas que surjan. Se trataba de realizar una comunicación por objetivos, en la que los objetivos de la organización y los objetivos individuales alcanzasen el mayor grado de coherencia, incluso de proximidad.

En la segunda mitad del siglo XX aparecen las Teorías Sistémicas de la Organización. Se admiten y empiezan a estudiar desajustes y conflictos entre los sujetos internos y también externos de la organización. La organización se ve como un sistema complejo, en el que los procesos, las interrelaciones, el entorno, los valores, etc. tienen una importancia y una influencia crecientes. La comunicación interna y externa, como se empezó a decir por entonces, alcanza un valor clave en la identificación de valores, intereses, objetivos de unos y otros sujetos, constatando que con frecuencia entre unos y otros hay más tensiones y divergencias de las previstas. Las viejas teorías racionalistas, de corte jerárquico y unidireccional, así como las teorías funcionalistas, basadas en teorías motivacionales y de búsqueda de rendimientos tanto colectivos como personales, empiezan a ser consideradas como insuficientes. La comunicación va ser en buena medida el entorno en el que se vehiculen e integren las nuevas demandas sociales y culturales en el cambio del milenio.

En la actual situación de crisis generalizada e insatisfacción creciente de la sociedad de la globalización, donde la internacionalización de capitales, estrategias y alta tecnología no están dando resultados satisfactorios ni tan siquiera para los ciudadanos del llamado primer mundo, la comunicación hipertecnológica es un nuevo atavismo y rutina en el que las posibilidades de cohesión social aumentan tanto como sus problemas de denuncia social. La ciudadanía se sabe cosmopolita y consciente de su papel crítico y corresponsable con las organizaciones. En este contexto emergen los estudios de ética del consumo y de la comunicación, como los de Adela Cortina, y los dedicados a la gestión ética de la implicación de la sociedad global (Martínez J.J. 2007).

Así, la comunicación ha devenido de ser vertical, a ser simpática, después empática, más tarde retroalimentada y transversal, para ser exigida cada vez más en nuestros días como responsable, solidaria y transformadora.

\section{Bases para una comunicación responsable}

La comunicación, hoy entendida en el marco de la RSE, tiene un sentido estratégico y por tanto un carácter planificado o de proyecto, y un sentido de mediación con la comunidad. Para que la comunicación no fuera un ámbito simplemente instrumentalizado por la RSE y las organizaciones, habría de encontrar también su papel en la propia visión corporativa en relación con la comunidad, y definirla desde su finalidad social.

En este marco, la comunicación en las organizaciones pasaría de ser definida por sus objetivos a incorporar fines, de ser plural a ser divergente, de ser transversal a ser circular, de ser eficaz a ser solidaria, de ser rentable a ser sostenible, de ser correcta a ser responsable.

Tomamos pues, como definición de partida de comunicación responsable la integración de los elementos esenciales de la Responsabilidad Social, esto es, el proyecto y planificación de un 
diálogo mediado, finalista y comprometido, entre ciudadanos. Definición ésta que puede desarrollarse atendiendo a cada término implicado:

Proyecto. Un proyecto consiste en la ordenación de un conjunto de actividades interrelacionas entre sí (Baizán, 2002:8). Todo proyecto incluye un conjunto de ideas, de iniciativas, considerando los recursos necesarios para su ejecución, pero siempre en función de una finalidad. Un proyecto es un proceso intencional, es una visualización o una representación anticipada de una idea, de una iniciativa. Dado que todo proyecto combina recursos humanos, materiales, financieros y técnicos, los proyectos sociales se caracterizarían no sólo por sus objetivos, sociales o solidarios, sino por la prioridad y compromiso muy especialmente en el ámbito de las personas. El proyecto es proceso, pero, para superar una concepción meramente mecanicista del mismo, en la comunicación el proyecto debe enfocarse desde la perspectiva de la persona, como principal dinamizador del ideograma que se anticipa. La idea de proyecto implica también una planificación, concepto que desarrollamos más adelante.

Diálogo. Comunicación, frente a información, implica correspondencia, simetría, equiparación de situaciones, circularidad. De ahí que la comunicación responsable no pueda ser unidireccional, sino que se sugiera, espere y atienda una respuesta, que se comunique por atención prioritaria a los públicos. El término sinónimo adecuado para no incluir la palabra a definir dentro de la definición (comunicación) sería el de diálogo. Lo dialógico siempre supera las carencias de la unicidad y la unidireccionalidad. Dialógico como lógica de lo que es, se identifica y consensúa, entre dos o más partes iguales e interlocutores. De ahí que una actitud dialógica es también una actitud autocrítica, ya que toda pregunta tiene dirigirse hacia uno mismo en primer lugar para ser siquiera entendida. El diálogo no es una mera argucia para convencer, ni un mero procedimiento retórico para bien aparecer de cara a un público expectante y ajeno, el diálogo no es una mera teatralización en la que cada personaje representa un papel previamente asignado por un poder autoritario o por una mera conjunción azarosa de circunstancias. El diálogo no es un mero ajuste de herramientas para enmascarar el logro de intereses, incluso legales, pero no solidarios. La actitud dialógica en comunicación es una aventura compartida en pos de un fin a concretar en cada momento (Gadamer, H. C. 1984:457-458) y del que al inicio tan sólo constatamos la preocupación, la tensión o la carencia respecto al contexto común, sea social, laboral, medio ambiental, en fin, referido a los Derechos Humanos. Frente a la vieja hegemonía de emisores y medios, la comunicación responsable priorizaría a los públicos (no sólo a los destinatarios, sino a todas las personas implicadas en el proceso de comunicación) y actuaría por atención prioritaria a ellos.

El diálogo, cada vez más, se trata entre públicos activos y no entre meros emisores y receptores. Se adopta cada vez de forma más activa y competente una actitud crítica, reivindicativa y dialógica (Habermas, J. 1981:65)

Mediación. Es importante destacar la idea de los medios de comunicación no tanto como difusores, sino como mediadores influyentes en la configuración social (Nos y Gámez, 2006:13). El concepto de mediación implica toda una serie de ideas: correspondencia, igualación, interacción, integración, pluralidad, alteridad entre a y b. Un puente siempre relaciona y altera, en su sentido más etimológico, la relación, y esa relación es su- 
peradora de la distancia entre dos partes. El concepto de mediación no es pues una mera solución mecánica ni tecnológica, no es sólo un canal indiferente y neutro por el que fluye indistintamente una información u otra, sino la vía de superación de posiciones opuestas, el acercamiento de posiciones alejadas. Ya Habermas hablaba de la bidireccionalidad para que haya comunicación activa, participativa, crítica y responsable. Hoy incluso recurrimos a las llamadas lógicas polivalentes, divergentes o difusas para conformar un paradigma de comunicación abierta y corresponsable. La llamada interactividad de los medios digitales está empezando a visualizar la propuesta habermasiana de "la concurrencia pública de argumentos privados en calidad de consenso acerca de lo prácticamente necesario según el interés general" (Habermas, J. 1981:118)

La Comunicación Responsable en el ámbito de la Responsabilidad Social de las organizaciones está realizando aquellos viejos ideales ilustrados en los medios, considerador como espacio público, como expresión pública del debate de las ideas y como necesario conflicto de argumentos en términos contrastables, consensuables y universales.

Por ello parece insuficiente reducir la Comunicación Responsable a las labores de gabinete de prensa. Aunque extender la cultura de la RSE a los medios de comunicación, especialmente a la prensa económica, puede contribuir sobremanera a su desarrollo debido a que la información económica sobre las empresas debe ser aproxima a los ciudadanos (accionistas, consumidores, inversores, etc.). En las Recomendaciones 54, 55 y 57 del Libro Blanco, al mismo tiempo, se propone que la información sobre la RSE debe ser independiente y crítica, y aunque la mayoría de medios de comunicación españoles presentan una sección relativa a RSE o RSC, sin embargo lo siguen tratando con cierto recelo y algo de desconocimiento, según estudios de Emilio José García Vílchez y Oscar J. González Alcántara. ${ }^{8}$

Finalismo. No se pretende reintroducir viejos debates teleológicos, pero es cierto que la mercantilización de la información, con todos los vicios derivados de las luchas de poder en el seno de las llamadas industrias culturales, hace que la comunicación se pervierta en un mero ámbito de consumo simbólico y el ciudadano se vea reducido a un mero consumidor privado de mensajes. Cuando la comunicación se permuta en una conducta social acrítica y prefabricada desde instancias de poder difusas e invisibles, el problema de los fines vuelve a renacer en su toda su divergencia entre objetivos y fines, entre medios y fines. La interpretación capitalista de los públicos a meras audiencias, los convierte en objeto de venta. La reflexión sobre la llamada Sociedad del Espectáculo, que introdujera G. Debord, nos advierte que el ocio se convierte en negocio, la participación se reduce a una llamada en el concurso, el debate sobre las libertades públicas se reduce a un mero cotilleo malsano sobre la privacidad ajena.

El rasgo de finalismo en la Comunicación Responsable plantea la necesidad de los fines como orientadores de la gestión de la comunicación, más allá de los meros intereses privados, cortoplacistas y demagógicos. Por lo que la Comunicación Responsable se realiza no es sólo para la mera consecución de unos objetivos, sino para la autorrealización en el propósito de aspirar a unas finalidades que nos orientan y motivan per-

8 García Vílchez, Emilio José y González Alcántara, Oscar J.: El Libro Blanco de la Responsabilidad Social de las empresas en España. Mercaredsostenible. Disponible en http://www.mercaredsostenible. com/normativas-internacional/el-libro-blanco-de-la-responsabilidad-social-de-las-empresas-en-espana 
sonal e institucionalmente en todo el proceso. En la Constatación 1 del Libro Blanco sobre la RSE se comenta que no hay una foto fija para la RSE, no tiene una meta, es una mejora continua, un camino hacia la excelencia en todos los planos.

Compromiso. Construido sobre la definición de valores solidarios compartidos y para el fomento de los mismos, aceptados voluntariamente por los agentes que participan en la comunicación y con el convencimiento de los mismos, no así mediante la imposición ni mera asunción de los mismos.

La Comunicación Responsable asume como de su marco de referencia aquellos problemas tanto globales como locales y que la nueva ciudadanía reclama para su resolución, tales como: las enormes y crecientes desigualdades de todo tipo; la creciente crisis de las vías de participación efectiva en todos los ámbitos de la vida, el deterioro del medio ambiente por la falta de control sostenible de la producción y del consumo.

Ciudadanía. Ciudadanía implica la idea de un sujeto activo, participativo, crítico, transformador, creador de comunidad. Con este término como referencia se superan las carencias de los identificadores de públicos participantes usuales y también necesarios de los distintos paradigmas: receptores, destinatarios, consumidores, público objetivo, target, audiencias, públicos internos y externos, stackeholders, etc.

Esta síntesis entre economía y ciudadanía tuvo el punto de inflexión en la iniciativa presentada por el anterior Secretario General de las Naciones Unidas, Kofi Annan, ante el Foro Económico Mundial en Davos (1999) donde se promovía la adhesión de empresas al Pacto Mundial (Global Compact) por parte de la ONU, con el objetivo de "crear una ciudadanía corporativa global, que permita la conciliación de los intereses y procesos de la actividad empresarial, con los valores y demandas de la sociedad civil, así como con los proyectos de la ONU, Organizaciones Internacionales sectoriales, sindicatos y ONGs".

No hace tanto tiempo que el concepto de público venía determinado por la exclusión, la información era "propiedad" de aquellos sujetos que no sólo ostentaban la titularidad jurídica de los bienes de producción, sino de la capacidad unidireccional de producción de mensajes y el control de la distribución, así como la pertinencia y dominio de los códigos (Eco, U. 1982: 286). Pero el "empequeñecimiento del mundo" en términos de Paul Virilo (2005:15), hace que no sólo la velocidad de toda información sea accesible en "tiempo real", sino que la discriminación entre información, comunicación y conocimiento sea un problema de máxima gravedad. La ampliación de la esfera pública de la información conlleva el incremento de la llamada "intoxicación informativa". La dificultad de la interlocución, el desprestigio de los sujetos tradicionales de la comunicación, como son los mismos titulares de derechos tradicionales privados, como empresarios, o públicos, como los Estados, la complejidad de la interargumentación en los mensajes, etc. hace que plantear y reivindicar la responsabilidad en toda comunicación sea de extrema necesidad u urgencia.

Aquí cabe introducir la necesidad de replantear nuevas formas de ciudadanía que aprovechando las nuevas posibilidades tecnológicas de la red informática esté postulándose como una nueva "opinión pública cosmopolita", que aspira en ese juego dialéctico de lo global y lo local, a convertirse en nuevos interlocutores de las deliberaciones de las nuevas preocupaciones que cada día más nos interesan y acucian. Por ello, el 
debate sobre la nueva ciudadanía es una de las piezas clave de la Comunicación Responsable.

\section{Conclusiones a las implicaciones del concepto de comunicación responsable}

Una de las conclusiones más importantes del Libro Blanco es la de considerar la transparencia y la comunicación como elementos claves de la RSE:

8. La transparencia y la comunicación de las acciones de la empresa hacia la sociedad han sido señaladas como una potente palanca de cambio. Por un lado para estimular el cambio interno empresarial, que encuentra en la comunicación de sus logros un acicate para trabajar por ellos y la culminación de un proceso de gestión. Y por otro lado como una posibilidad que la sociedad tiene de reconocer y, en su caso, recompensar a las empresas más responsables o castigar a las que percibe que no lo son. Por esa doble función, transparencia y comunicación fueron señaladas en las comparecencias como elementos claves de la RSE.

La gestión y la comunicación responsables se compensan y suelen ubicarse en un mapa conceptual que se podría sintetizar de la forma siguiente: Se parte de considerar que la empresa por el mero hecho de serlo y por el importante papel que juega en la creación de empleo y de riqueza, ya es por sí misma responsable, si cumple las leyes. Una empresa que aplica la RSE es una empresa responsable en sus tres vertientes (en lo económico, en lo social y en lo ambiental). Además, se preocupa por la relación con todos sus grupos de interés de la compañía y la sociedad en su conjunto, mediante consulta y presentando de forma transparente cómo opera en esas tres vertientes (lo que se denomina Triple Cuenta de Resultados). De esta manera, la empresa adquiere una reputación, que no sólo consiste en la suma de los activos intangibles sino también en la capacidad de comunicar estos activos a los grupos de interés. Estos últimos confían pues en la empresa, dándole licencia para crecer y ser más competitiva, en definitiva, transformándose en una empresa sostenible (González Alcántara O. J.; Fontaneda González I.; Mariscal Saldaña, M. A.; Miralles Insa, M. 2007).

Pero podríamos decir que este es el mapa de mínimos en el que se cruzan algunos conceptos fundamentales, como: Responsabilidad Social, Comunicación Responsable, Identidad y Reputación Corporativas. Pero más allá del cumplimento estricto de la legalidad, la comunicación responsable vendría a retomar el viejo concepto de Moralidad sobre la Legalidad.

Como conclusión a este texto aportamos una definición de máximos, con un algo grado de proyectividad e idealidad de la RSE, en una definición entornada hacia el ámbito de los Derechos Humanos:

La Comunicación responsable podría ser entendida como el diálogo de organizaciones con públicos que se hacen partícipes de los procesos y efectos derivados de las relaciones entre esa persona/organización/empresa y la comunidad. Dicha corresponsabilidad parte de la asunción de unos fines sociales compartidos, continuamente redefinidos y consensuados a partir de dichas relaciones. Mantener la visión puede ser más importante que cumplir los objetivos y posibilita la reorientación de estrategias equivocadas.

Hablar de comunicación responsable implicaría lo siguiente:

- Es una decisión voluntaria de la empresa, sumativa al gobierno y gestión habituales, replanteando el concepto de Buena Gobernanza 
- Tiene un sentido procesal e instrumental que cualifica sus estrategias, políticas y procedimientos, reorientando sus objetivos estratégicos y operativos en el ámbito de su actividad y producción sea material e inmaterial

- Integrando en su identidad y actividad las preocupaciones sociales, laborales y medio ambientales.

- La integración de los Derechos Humanos se establece con un condicionante de respeto y por tanto de mayor imperatividad y no sólo de mera receptividad o sensibilidad a las preocupaciones dominantes antes enumeradas

- Convendría recordar que de la misma forma que es de obligado cumplimiento la legalidad laboral, social o medio ambiental pertinente en cada caso y momento, también es de obligado cumplimiento cumplir con los textos de los Derechos Humanos, considerando que estos cumplimientos son previos a la voluntaria decisión de la Responsabilidad Social asumida.

- La comunicación responsable se sitúa en un marco de relaciones complejas entre los diferentes sujetos que intervienen en la producción, gestión e interacción en el triple contexto antes comentado. Es más, la relación se especifica como dialógica, lo que implica una semántica muy cualificada. Diálogo es igualdad, paridad, horizontalidad, participación, interacción efectiva, entre otras cualidades.

- Los grupos de interés se entienden como grupos de ciudadanos activos y sensibles en una sociedad abierta, participativa, sostenible en el marco de al globalidad, más allá de intereses inversores, financieros o de participación en la actividad de la empresa. Esto es, públicos corresponsables.

- Solo en el contexto de una comunicación responsable alcanzan significado los conceptos de transparencia y de responsabilidad mutua, o sea, de corresponsabilidad.

Finalmente, este argumentarlo tendría escaso valor si no concluyese en la asunción de responsabilidades por las consecuencias e impactos derivados de las acciones comunicativas realizadas por la empresa en cuestión. Sería de interés recordar que en una relación dialógica la responsabilidad se propone como corresponsabilidad y que la responsabilidad es tanto o más finalista que meramente objetivista. Por eso la inclusión del concepto de impacto tiene una dimensión más futurible que de pasado, lo que plantea el serio problema de los procedimientos de medición de los impactos generados en cualquiera de los ámbitos, preocupaciones y respeto antes indicados. 


\section{Bibliografía}

Andrés del Campo, Susana de (2007). El nuevo papel de los públicos en el sistema publicitario. En Alvarado, M.C. y Martín, M.I.. (coords.). Nuevas tendencias en la comunicación publicitaria (pp.61-77). Zamora: Comunicación Social Ediciones.

Andrés del Campo, Susana de (Coord.). (2009): Otros fines de la publicidad. Zamora-Salamanca: Comunicación Social Ediciones.

Andrés del Campo, Susana de y González Martín, Rodrigo (2010). Comunicación responsable y transferencia social: Retos y compromisos en la formación de nuevos perfiles profesionales en comunicación con fines sociales. En Sierra Sánchez, Javier y Cabezuelo Lorenzo, Francisco (Coords.). Competencias y perfiles profesionales en los estudios de Ciencias de la Comunicación (66-81). Madrid: Fragua.

Aristóteles (1988). Política. Traducción Manuela García Valdés. Madrid: Gredos.

Baizan, Evaristo (dr.) (2002). Cómo elaborar un proyecto. Cuaderno de Orientacion no 17 . Oviedo: Centro Regional de Información y Documentación del Principado de Asturias.

Battram, Arthur (2001). Navegar por la complejidad. Barcelona: Granica.

Carcelén García, S., Ruíz San-Román, J.A. y Villagra García, N. (2002). Las posibilidades reparticipación de los ciudadanos en campañas institucionales de comunicación mediante páginas web. En Diezhandino, P., Marinas, J.M. y Watt, N. (Coords.).Ética de la comunicación: problemas y recursos (109121). Madrid, Edipo.

Comisión de Trabajo y Asuntos Sociales (2006). Libro Blanco para potenciar y promover la responsabilidad social de las empresas. BOE No 424, 4-8-2006 3-112

Comisión de las Comunidades Europeas (2001). Libro Verde: Fomentar un marco europeo para la responsabilidad social de las empresas. Bruselas, 18.07.2001. Disponible en

http://www.jussemper.org/Inicio/Recursos/Actividad\%20 Corporativa/Resources/Libro\%20verde.pdf

Cortina, A.(2002). Por una ética del consumo. La ciudadanía del consumidor en el mundo global. Madrid: Taurus.

DIRCOM (2009). La comunicación responsable. Clave para el fomento de la RSE, Barcelona: DIRCOM.
Eco, U. (1982). ¿El público perjudica a la televisión? En VV.AA.: Sociología de la comunicación de masas (172-184). Barcelona: Gustavo Gili.

Gadamer, H.C. (1987). Verdad y método. Salamanca: Sígueme. González, Marcos (2009). La comunicación responsable, clave para el fomento de la RSE, Barcelona: DIRCOM.

González Alcántara O.J.; Fontaneda González I.; Mariscal Saldaña, M.A.; Miralles Insa, M. (2007). El Libro Blanco de la RSE en España: la gestión de empresas desde la Responsabilidad Social. En ADINGOR. XI Congreso de Ingeniería de Organización - Internacional Conference on Industrial Engineering and Industrial Management, CIO (pp. 160-187). CD de comunicaciones (Tema: Ética y responsabilidad social).

González Esteban, Elsa (2001). La responsabilidad moral de la empresa: una revisión de la teoría de stakeholder desde la ética discursiva, Tesis doctoral, Castellón: Universidad Jaume I.

Habermas, J. (1981). Historia y crítica de la opinión pública. Barcelona. Gustavo Gili

Lucas Marín, A. (1997). La Comunicación en la empresa y en las organizaciones. Barcelona, Bosch.

Manucci, Marcelo (2004). Comunicación corporativa estratégica. Bogotá: SAF Grupo.

Manucci, Marcelo (2005). Narraciones corporativas: Comunicación, estrategia y futuro en las organizaciones. Técnica Administrativa, Buenos Aires, Volumen 4 Número: 21, marzo/abril. Disponible en http://www.cyta.com.ar/ta0403/ v4n3al.htm

Martínez J.J. (2007). Libro de apuntes de la asignatura "Calidad en la Industria" de $2^{\circ}$ curso de Ingeniería de Organización Industrial de la Universidad de Burgos. Publicaciones UBU. Disponible en http://www.mercaredsostenible.com/ normativas-internacional/el-libro-blanco-de-la-responsabilidad-social-de-las-empresas-en-espana

Nos Aldás, Eloísa, y Gámez Fuentes, Ma José (coords.) (2006). Medios de comunicación y solidaridad. Reflexiones en torno a la (des)articulación social, Castelló de la Plana: Universitat Jaume I.

Villagra García, Nuria (ed. Lit.) (2005). La comunicación de la responsabilidad social corporativa: memoria académica, curso 2004-2005, Universidad Pontificia de Comillas.

Virilo, Paul (2005). Lo que viene. Madrid: Arena libros. 
